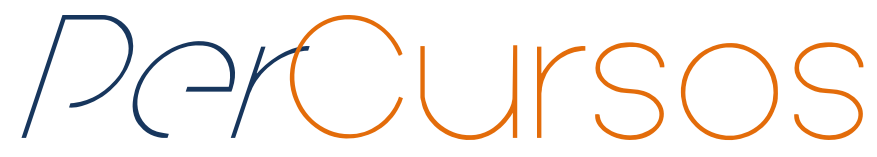

\title{
Territorialidades e produção de paisagens em UCS: estudo de caso no extremo Sul da Ilha de Santa Catarina
}

\section{Resumo}

Entendendo-se a paisagem como uma percepção do ambiente de acordo com o ponto de vista de um determinado observador, onde o homem constitui-se, ao mesmo tempo, em parte integrante e transformante, observa-se que a implantação de uma Unidade de Conservação (UC), por si só, é um ato de produção de paisagem. Entremeando esta construção contínua, encontram-se as territorialidades, entendidas com base nas relações de poder de diferentes grupos, que se constituem na essência determinante do controle territorial destes grupos sobre determinadas áreas. O estudo de caso apresentado aponta subsídios para elaboração de um ensaio sobre o efeito de novas territorialidades oriundas da criação e implantação de UCs sobre a produção de paisagens. O fato de se institucionalizar um determinado espaço, por si só, não garante a manutenção de paisagens naturais, sendo que a quebra das relações de territorialidade, ou seja, a quebra da materialização prática das relações de um grupo social com o meio natural, das relações quotidianas de grupos locais, serve como um fator a mais de produção da paisagem. No caso da Área de Proteção Ambiental (APA) do Entorno Costeiro do Parque Estadual da Serra do Tabuleiro, na Ilha de Santa Catarina, objeto deste estudo de caso, a produção da paisagem não foi desencadeada pela criação desta UC, já que a mesma foi implantada após o abandono e início da regeneração natural da vegetação. No entanto, considera-se que a institucionalização daquela área contribuiu para a manutenção da re-naturalização da paisagem, sendo as territorialidades os principais fatores atuantes.

Palavras-chave: Territorialidade; Produção de paisagens; Unidades de conservação; Extremo sul da Ilha de Santa Catarina.

\author{
Alexandre Felix \\ Doutorando no Programa de Pós- \\ graduação em Geografia - PPGG, \\ Universidade Federal de Santa \\ Catarina - UFSC. \\ Brasil \\ afelix.geo@gmail.com
}

\section{Daniella Zatarian}

Arquiteta e Urbanista.

Brasil

dani.zata@gmail.com

\section{Para citar este artigo:}

FELIX, Alexandre; ZATARIAN, Daniella. Territorialidades e produção de paisagens em UCS: estudo de caso no extremo Sul da Ilha de Santa Catarina. Revista PerCursos. Florianópolis, v. 16, n.30, p. 162 - 184. jan./abr. 2015 .

\section{DOI: 10.5965/1984724616302015162}

http://dx.doi.org/10.5965/1984724616302015162 


\title{
Territorialities and landscapes production in conservation units: a case study in the Southern end of the Santa Catarina Island
}

\begin{abstract}
It is observed that the establishment of a conservation unit in itself, is an act of production landscape, which is understood as a environment perception point of view of a particular observer, being the man is a transforming an integral part to same time. In this sense, territorialities are understood on the basis of power relations of different groups, determining their territorial control on specific areas. The effect of new territorialities derived from the establishment of conservation units on the production of landscape is observed in this case study. It was observed that the institutionalization of space does not warrant the maintenance of natural landscapes. Rather, the breakdown of relationships of territorialities, the practice of everyday relations of a social group with the natural environment, serves as one more factor that production of the landscape. In this case study, Environmental Protection Area of the Coastal Surrounding of the Serra do Tabuleiro State Park on the Santa Catarina Island, the production of the landscape did not come for the creation of the conservation unit because the area had been abandoned and becoming to the natural regeneration of vegetation. However, it is meant that the institutionalization of the area contributed to the maintenance and return to natural landscape, and the territorialities the main factors acting for this.
\end{abstract}

Keywords: Territorialities; Production of landscapes; Conservation units; Southern end of the Santa Catarina Island. 


\section{Introdução}

Os estudos sobre a trajetória de diversas civilizações pretéritas, como os Maias, os Rapanui e os Vikings, por exemplo,apontam que,entre os fatores ocasionadores de seus declínios,encontram-se a falta de capacidade em regular ou criar mecanismos internos de autorregulação ambiental, capazes de promover o desenvolvimento sem esgotar seus recursos básicos de manutenção.

$\mathrm{Na}$ atual civilização ocidental, observa-se o resultado de uma evolução secular de grupos sociais, em que o modocapitalista de produção tende à crescente utilização de recursos mineras e naturais. Com esta premissa, baseada em um conhecimento técnicocientífico cada vez mais acurado, tende-se a desafiar mais os limites de exploração destes recursos.Associado a este cenário, têm-se as problemáticas relacionadas às extinções de fauna e flora, aos sinais de exaustão de recursos minerais não renováveis e ao aumento das temperaturas médias mundiais e consequente aquecimento global.

Neste contexto, surgem deliberações e iniciativas governamentais sobre a questão ambiental, em parte, impulsionadas pela necessidade de criação de mecanismos internos de autorregulação, que visam uma meta cada vez mais desafiadora, que é a manutenção do modo de produção atual.

Muito antes de conferências internacionais como Estocolmo 1972, Rio 1992, Protocolo de Quioto e Johannesburgo 2002, as ações conservacionistas governamentais mais antigas, senão as pioneiras,referem-se àcriação e implantação de Unidades de Conservação da Natureza - UCs. Como exemplos, citam-se a implantação do Parque Nacional de Yellowstone (EUA, instituído em 1872) e do Parque Nacional de Itatiaia (BRASIL, instituído em 1937).

O ideário de UCs foioriginalmente desenvolvido com vistas à salvaguarda de áreas silvestres, sendo que as UCs podem ser definidas como áreas instituídas e protegidas por força de Leis(Federais, Estaduais ou Municipais), as quais determinam seus limites físicos e onde os recursos naturais existentes possuam qualidades de interesse à preservação. 
De acordo com Röper (1999), do ponto de vista geográfico, uma UC pode ser entendida como uma "forma de institucionalização do espaço e uma expressão do seu controle político". Esta institucionalização de espaços, teoricamente,seria a responsável pela manutenção de paisagens ditas "naturais", ao passo que impõe uma série de restrições em relação à ocupação e uso do solo em uma determinada área. Portanto, a regulamentação imprime o conceito de espaço territorializado, ou, territorialidade.

No presente trabalho, propõe-se analisar a produção de paisagens através das novas territorialidades oriundas da institucionalização de áreasefetivada a partir de UCs. Pretende-se abordar a forma pela qual os aspectos culturais de apropriação e transformação do espaço, vinculados aos modos de vida instituídos, permeiam este intrincado processo.

\section{Territorialidades e paisagens culturais}

Definida por Sauer (1925, p. 300) como "uma área composta por uma associação distinta de formas, ao mesmo tempo físicas e culturais", a paisagem pode ser entendida, em um primeiro momento, como a percepção do ambiente de acordo com o ponto de vista de um determinado observador, onde o homem constitui-se, ao mesmo tempo, em parte integrante e transformante.

De acordo com Claval (2001, p. 14), a paisagem é modelada pelo conjunto de técnicas dominadas pela sociedade e serve como um "documento-chave para compreender as culturas". Assim, subentende-se o conceito de acumulação e sobreposição histórica de formas,expresso por Santos (1996), que remete à artificialização do natural, ou seja, uma inserção crescente das formas antropizadas sobre a natureza original, de acordo com a evolução técnico-científica de cada sociedade.

Desta maneira, a paisagem pode oferecer condições de se entender a realidade espacial, em certo momento e em um determinado lugar, recebendo valores diversos de acordo com o sujeito que a percebe, pelo maior ou menor grau de vivência e conhecimento sobre a área observada e do ponto de vista de onde é feita esta observação. 
Neste sentido, a materialização prática das relações de um grupo social com o meio natural, fator determinante da produção de paisagens,pode ser definida através de territorialidades locais.

A ideia de territorialidadeencontra-se atrelada ao conceito de território que, de acordo com Souza (1995, p. 78), pode ser entendido como "um espaço definido e delimitado por e a partir de relações de poder". Estas relações de poder são apreendidaspelo autor como "um campo de forças, uma teia ou rede de relações sociais que, a par de sua complexidade interna, define, ao mesmo tempo, um limite, uma alteridade" (SOUZA, 1995, p. 86). Os territórios, segundo o autor, podem ser construídos e destruídos dentro de escalas temporais diversas, apresentarem existência regular ou cíclica e possuírem limites instáveis ou estáveis.

Sendo assim, a territorialidade pode ser definida com base nas relações sociais quotidianas de diferentes grupos, que se constituemna essência determinante do controle territorial destes grupos sobre determinadas áreas (SACK, 1980; SOUZA, 1995; COSTA, 2004). Estas relações imprimem, por consequência, as impressões características que irão integrar e diferenciar as diversificadas paisagensculturais resultantes.

\section{Unidades de conservação e as novas territorialidades}

Para Souza (1995, p. 99), a territorialidade se justifica como "aquilo que faz de qualquer território um território". Neste sentido, verifica-se que a implantação de uma UC sobre um determinado espaço provoca, inquestionavelmente, uma alteração no jogo de forças que regem o lugar.

Após a implantação de uma UC, as relações sociais alteram-se devido a um conjunto de regras ditadas por um novo agente (no caso, o Estado), que passa a exercer as funções determinantes de controle territorial, sobrepondo-se ou contrapondo-se, em um primeiro momento às territorialidades existentes e proporcionando o surgimento de inúmeros conflitos. 
Desenvolve-se, portanto, uma nova territorialidade: o espaço passa a ser considerado um território institucionalizado dominado pelos outsiders, não mais o lugar da materialização das relações sociais dos insiders (SOUZA, 1995).

No entanto, a sustentação do domínio territorial somente é obtida através da manutenção do controle sobre a área. Por sua vez, esta manutenção, como bem adverte Arendt (1985, apud SOUZA, 1995), requer acima de imposições ou ostentações, a aceitação e o reconhecimento de um determinado grupo social,Ou seja, somente quando os grupos sociais que já possuem relações de territorialidade com as áreas declaradas como UCsentenderem como necessária a conservação destas áreas é que o controle territorial do Estado será respeitado, o território não será invadido ou ameaçado e a nova territorialidade será legitimada.

\section{Estudo de caso}

\section{Caracterização da área de estudo}

O Município de Florianópolis está localizado entre $27^{\circ} 10^{\prime}$ e $27^{\circ} 50^{\prime}$ de latitude Sul e $48^{\circ} 20^{\prime}$ e $48^{\circ} 35^{\prime}$ de longitude Oeste, ocupando uma área de 436,5 km² (IPUF, 2001). A Ilha de Santa Catarina possui uma morfologia diferenciada, caracterizada pela riqueza de formações Holocênicas e Pleistocênicas nas áreas de planícies e por modelados Précambrianos que formam o embasamento cristalino (HERRMANN; ROSA, 1991).

De acordo com Felix et al. (2004), as belezas naturais e as riquezas arquitetônicas, costumes e tradições, associadas ao desenvolvimento urbano característico das cidades litorâneas de colonização açoriana conferem às paisagens culturais da llha de Santa Catarina um aspecto bucólico. Segundo o Instituto de Planejamento Urbano de Florianópolis(IPUF,2001), 42\% do território do município é constituído por áreas protegidas como UCs e áreas de preservação permanente. O extremo sul da Ilha de Santa Catarina, parte integrante da Área de Proteção Ambiental (APA) do Entorno Costeiro doMosaico de Unidades de Conservação da Serra do Tabuleiro e Terras de Massiambu (Figura 1),constitui a área de estudo deste trabalho e destaca-se em todos os aspectos citados, ressaltando-se a Praia de Naufragados. 
Esta praia é a mais meridional da Ilha de Santa Catarina, sendocaracterizada como uma praia de enseada, incrustada entre dois promontórios rochosos (Ponta do Frade, a leste e Ponta dos Naufragados, a oeste). Apresenta uma extensão aproximada de 750metros, declividade média aproximada de $3^{\circ}$ e largura média variável que, em determinadas épocas do ano, pode atingir 15ometros em seu ponto mais a oeste (próximo à foz do Rio Naufragados) e cerca de 1ometros, em seu ponto mais a leste (FELIX, 2010).

A denominação do lugar está relacionada aos inúmeros naufrágios ocorridos na barra sul da Ilha de Santa Catarina, de forma mais intensa próxima a Ponta dos Naufragados, fatos estes que podem ser explicados pelo embate entre as fortes correntes marinhas com as águas calmas do canal (Baía Sul).

Adjacente à praia dos Naufragados observa-se a ocorrência de uma estreita planície costeira, com comprimento máximo de 850 metros no sentido NE-SW, largura média de 400 metros e altitude média de 4,8 metros, representando uma área de intensa deposição, com aporte de sedimentos marinhos praiais, eólicos, lagunares e fluviais, incrustada na reentrância do embasamento cristalino(FELIX, 2010).

Toda esta área é rodeada por encostas íngremes, recobertas por vegetação de Mata Atlântica exuberante. Apresenta quase nenhuma infraestrutura turística, resumindo-se a estabelecimentos de pequeno porte (restaurante/lanchonete). Na Ponta dos Naufragados encontra-se um Farol, no alto de uma elevação com33 metros de altitude, de onde se observam as ilhas e a Fortaleza de Araçatuba, a Ilha dos Papagaios Pequenos, o Tômbolo ou Ilha dos Papagaios Grandes e as praias da Pinheira e do Sonho, emolduradas pelas encostas das Serras do Leste Catarinense, formando paisagens naturais aprazíveis. 


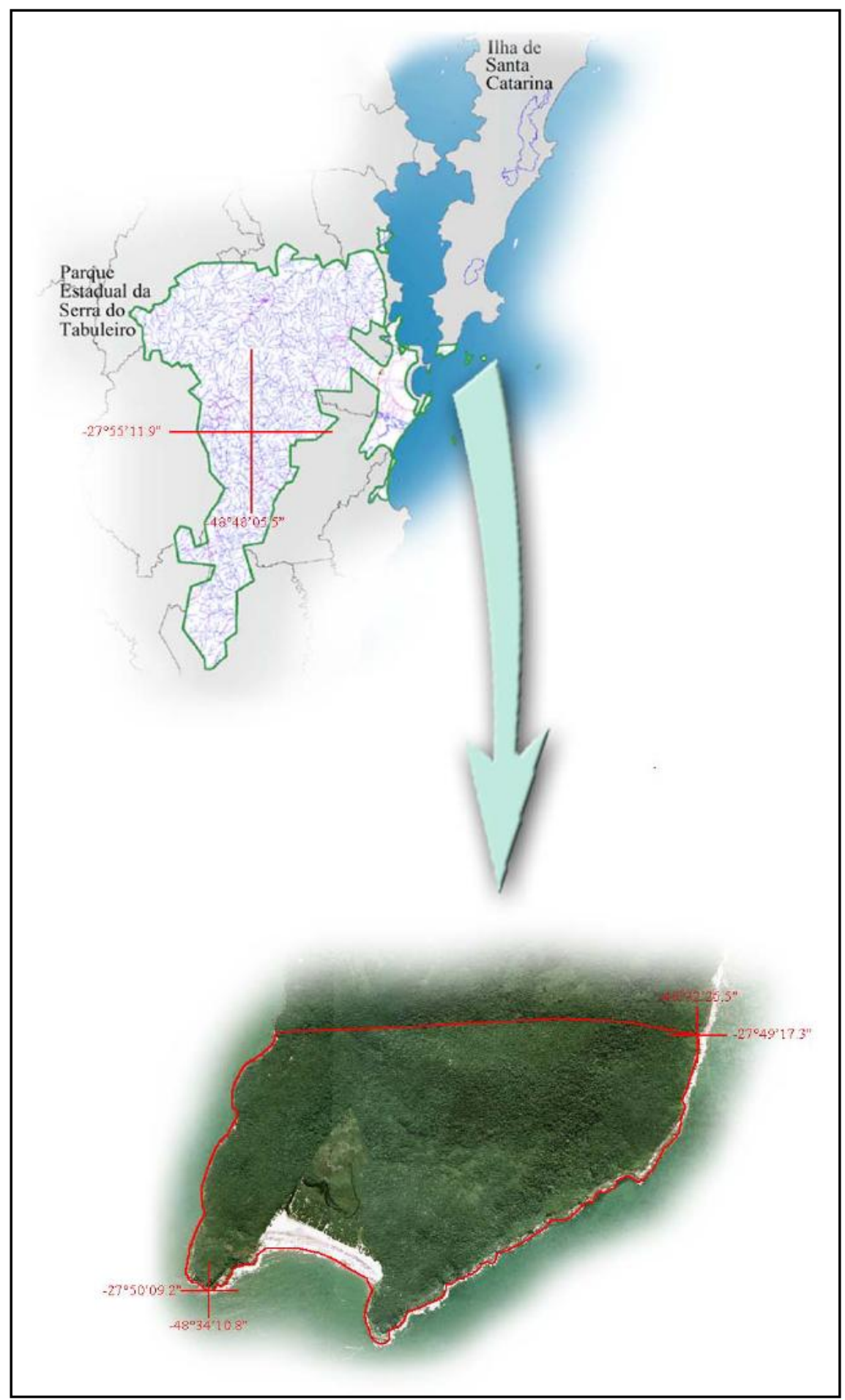

Figura 1 - Localização geográfica da Área de Proteção Ambiental (APA) do Entorno Costeiro o Mosaico de Unidades de Conservação da Serra do Tabuleiro e Terras de Massiambu na Ilha de Santa Catarina, delimitado pelo polígono vermelho no detalhe. Fonte: Elaborado pelo autor.

Para as avaliações da gênese e evolução da ocupação e uso do solo, bem como, das relações de territorialidade que impuseram as alterações da paisagem, serão analisadas as localidades da Tapera do Sul, Caieira da Barra do Sul, Saquinho e Rio das 
Pacas, que se constituem como porções integrantes da área de estudo, porém, atuando de forma indireta.

\section{Processo de ocupação e uso do solo}

Devido a sua localização estratégica, desde o início do século XVI, a Ilha de Santa Catarina se transformou em um dos principais pontos das rotas marítimas comerciais, sendo um local de parada para abastecimento de água e víveres.

No entanto, de acordo com vários autores (VÁRZEA, 1900; PEREIRA et al., 1991; PIAZZA, 1992; BOND, 1998), a ocupação na área de estudo está relacionada com a expansão do núcleo de colonos instalados na Freguesia do Ribeirão da Ilha que, por sua vez, foi efetivada a partir da grande migração provinda das ilhas do Arquipélago dos Açores, ocorrente entre os anos de 1748 e 1756.

Ao se estabelecerem em suas novas terras, uma das alternativas de sobrevivência encontrada pelos açorianos, foi o reaproveitamento das culturas (principalmente de mandioca e milho) abandonadas pelos indígenas e pelos primeiros núcleos vicentistas de ocupação, haja vista sua necessidade de resultados rápidos, frente à falta de estruturas que dispunham. Este aspecto evidencia a vivacidade do povo açoriano, por vezes, contestada e mal interpretada, como também, a importância do legado das culturas indígenas para a produção socioespacial e formação socioeconômica da llha de Santa Catarina, bem como, de todo litoral catarinense.

Segundo Pereira et al. (1991), as tecnologias dos moinhos de vento conhecidas pelos açorianos foram adaptadas para a criação dos engenhos, proporcionando a produção e comercialização de produtos manufaturados derivados da mandioca e da cana-de-açúcar, como a farinha de mandioca, o biju, o açúcar e a cachaça. Estes produtos manufaturados, juntamente com os excedentes agrícolas, fomentaram as primeiras relações comerciais e podem ser considerados como determinantes para a formação socioeconômica da cidade, que balizou suas atividades iniciais na produção, extração e comercialização dos víveres necessários e que possuíam demanda pelos navegadores que fundeavam nos portos desta região. 
Inquestionavelmente, estas atividades ocasionaram alterações na paisagem natural. Tarefa árdua, porém, seria a mensuração destas alterações e a determinação do grau de modificação ocorrido, aspectos que não constituem objeto deste estudo.

\section{Territorialidade açoriana e produção de paisagens}

Ao migrarem para a Ilha de Santa Catarina, os colonos que se instalaram receberam terras chanceladas pelas Provisões Régias Portuguesas, denominadas de Sesmarias. Nestas Provisões Régias, conforme bem relatado por Piazza (1992), as ordenanças relacionadas com os critérios de urbanização e ocupação do solo eram bastante específicas, incluindo as dimensões das próprias sesmarias, constituídas por um quarto de légua em quadro (equivalente a um quadrado com lado de aproximadamente 1.650 metros, totalizando 272,25 ha). No entanto, conforme abordado pelo autor, as dificuldades relacionadas à falta de profissionais habilitados para as demarcações eram inúmeras. Outro aspecto determinante foi a vontade dos colonos em se instalarem próximos uns dos outros, fazendo com que muitos se contentassem com áreas menores às sesmarias originalmente determinadas, fatores que ocasionaram necessárias reformulações nos padrões previamente definidos (PIAZZA, 1992).

Devido às grandes dimensões, constantemente as sesmarias transpunham as bacias hidrográficas. Nos setores de alta encosta das vertentes, em regiões bastante acidentadas e com solos pouco férteis, o relevo atuava, em muitos casos, como determinante no uso e ocupação do solo, sendo nestas áreas, apenas, explorados os recursos naturais existentes, como a madeira e a caça. Este fator induziuos novos colonos a se adaptarem às condicionantes geomorfológicas, passando a não ocuparem estas áreas nas porções de alta encosta e estabelecendo, desta forma, uma relação cultural de identificação e ocupação territorial.Para se entender estas restrições, basta imaginar as dificuldades que os colonos encontrariam quando tentassem transpor um divisor de águas, em região íngreme, movendo cargas pesadas (como toras) encosta acima.

Ao partilharem suas glebas, os herdeiros açorianos optavam por uma divisão da propriedade em tiras, imputando aspecto alongado às propriedades, que se estendem desde a porção frontal do terreno até a linha de cumeada. Na cultura germânica, por 
exemplo, como pode ser averiguada nas colônias alemãs em solo catarinense, a partilha de terras é realizada de forma bastante diferente, definindo-se talhões aproximadamente retangulares e que não se encontram, necessariamente, entre os limitantes frente e fundos de propriedades.

Nas localidades da Tapera do Sul, Caieira da Barra do Sul, Saquinho e Rio das Pacas, adjacentes à área de estudo e formadas por comunidades açorianas tradicionais, o vínculo atual de identificação com a bacia hidrográfica é demonstrado pelo fato de que estas representam os divisores territoriais dos lugares para os seus respectivos moradores. Este aspecto, caracterizado como uma espécie de herança cultural, determina a forma de ocupação e apropriação da terra, onde as relações de territorialidade que ocasionam a materialização das ações sociais se balizam aos limites impostos pela natureza: os divisores de águas.

Com esta premissa, a ocupação e uso do solo no extremo sul da llha de Santa Catarina desenvolveu-se em localidades individualizadas e incrustadas nas pequenas bacias hidrográficas, com seus limites territoriais bem definidos.

\section{A produção de paisagens no extremo sul da Ilha de Santa Catarina}

A forma de ocupação açoriana imprimiu suas marcas nas paisagens locais, onde quase toda extensão de vegetação natural de mata atlântica foi suprimida. Em primeiro momento, a vegetação nativa nas áreas de baixa e média encosta cedeu espaço para as edificações residenciais e às culturas de feijão, arroz, batata-doce, chuchu, alho, laranja, mandioca, café, cana-de-açúcar, banana e amendoim, além das demais áreas rurais destinadas às pastagens; posteriormente, deu-se a extração de lenha e toros de madeira de lei para produção naval e de móveis nas áreas de alta encosta(FELIX, 2005).

Devido à expansão das atividades rurais e aquecimento da comercialização dos produtos derivados, a partir de meados do século XXse fez necessário o acréscimo de áreas, a ampliação do território por parte das comunidades do extremo sul da llha de Santa Catarina, visando o aumento das culturas, principalmente, da mandioca. Neste momento, tornou-se extremamente necessária uma ampliação territorial por parte 
destes grupos locais em direção às áreas das bacias hidrográficas adjacentes e que não possuíam núcleos de ocupação, ou seja, não possuíam “donos”. A necessidade passou a suplantar o trabalho extra, necessário para exploração destas áreas anteriormente preteridas, resultando na expansão da ocupação, como pode ser evidenciado na Figura 2.

Segundo Felix (2005), esta ampliação aconteceu de forma simultânea por parte dos diferentes grupos adjacentes à área de estudo, gerando conflitos sociais por domínio de áreas. Após a resolução destes conflitos iniciais e o consequente surgimento de novas territorialidades, as relações de produção alteram as características originais da paisagem na área de estudo, atribuindo aspectos bastante semelhantes nestas novas áreas aos núcleos originais de ocupação, inclusive, com instalações de engenhos e demais edificações de apoio às atividades rurais e à pesca.

A partir da década de 1950, segundo Felix (2005), o crescimento do centro urbano do município de Florianópolis, entre outros fatores, foi o responsável pela atração de pessoas de diversas localidades, em busca de condições de trabalho melhores que aquelas encontradas no meio rural, além da estabilidade obtida com a remuneração fixa em dinheiro.

Em um primeiro momento, este processo acarretou em um fluxo de migração de caráter incipiente, devido à relativa proximidade da área com o centro urbano, propiciada pela abertura da estrada geral do Ribeirão da Ilha (atual Rodovia Baldicero Filomeno), que permitiu a criação de linhas regulares de transporte coletivo. Muitas pessoas, principalmente as mais jovens, obtiveram sucesso e deixaram de exercer suas funções agrícolas, diminuindo consideravelmente a força de trabalho necessária na produção rural frente aos meios empregados, que necessitavam de um número elevado de trabalhadores braçais. Começam a surgir grandes áreas de terras agrícolas abandonadas, como pode ser visualizado na Figura 3. 


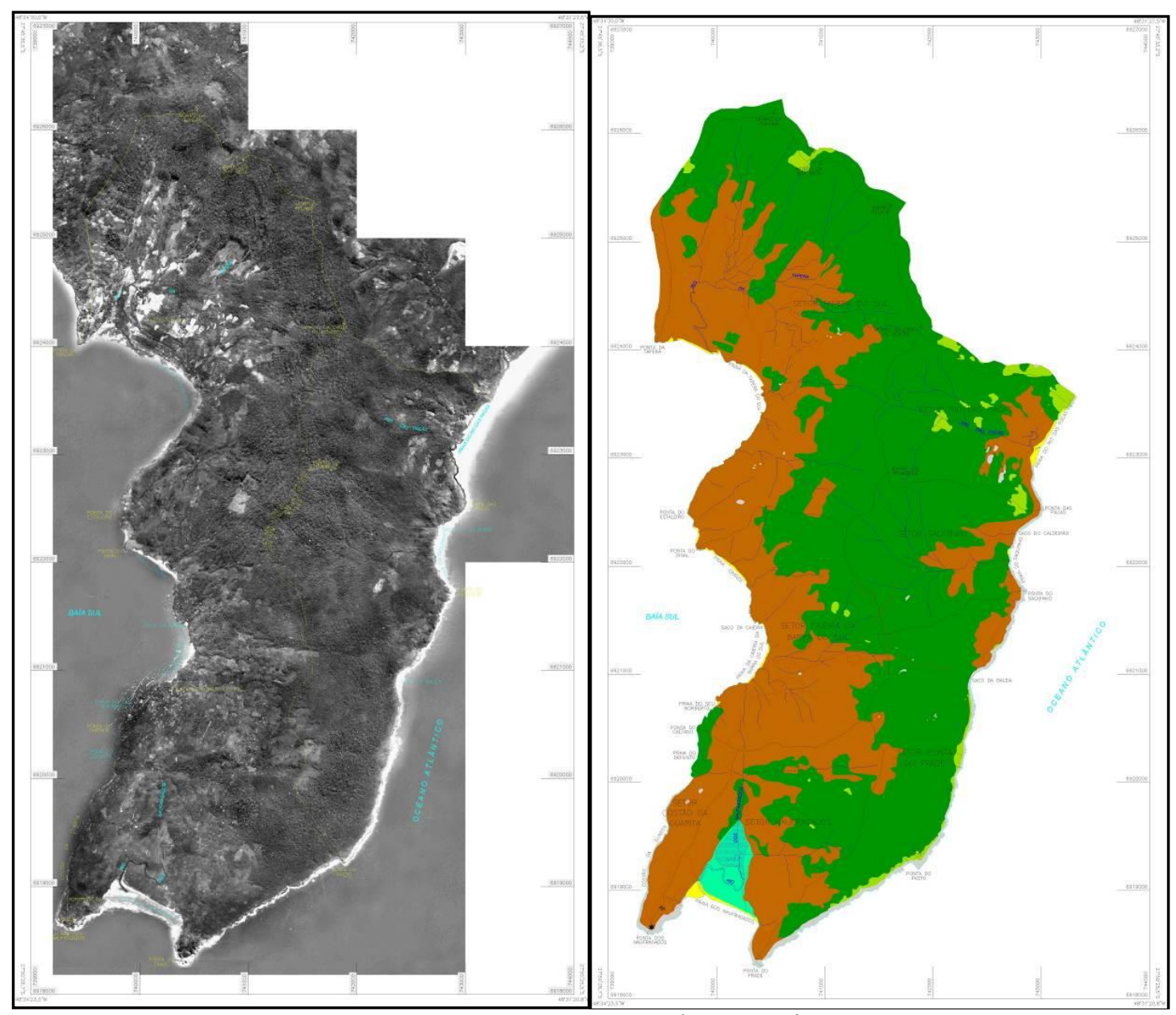

Figura 2 - Mosaico aerofotogramétrico do ano de 1938 (esquerda), com mapa de ocupação, uso e cobertura da terra (direita), onde se observa que as áreas em marrom representam as terras com usos agrícolas. Nota-se que grandes porções no interior da área de estudo (englobando todas as localidades adjacentes) apresentam usos relacionados à exploração rural. Fonte: Felix (2005).

De certo modo, observa-se a reprodução do fator global no local, ou seja, o esvaziamento das áreas rurais, provocado pelo crescimento de centros urbanos, atraindo a mão de obra existente no campo e atuando como determinante no processo de produção das paisagens. Grandes áreas de terras agrícolas abandonadas indicam uma queda na produção e consequente enfraquecimento das atividades econômicas baseadas no setor agrícola. No entanto, mantêm-se as relações de territorialidade: apesar de encontrarem-se "vazias", as terras ainda possuíam "donos". 


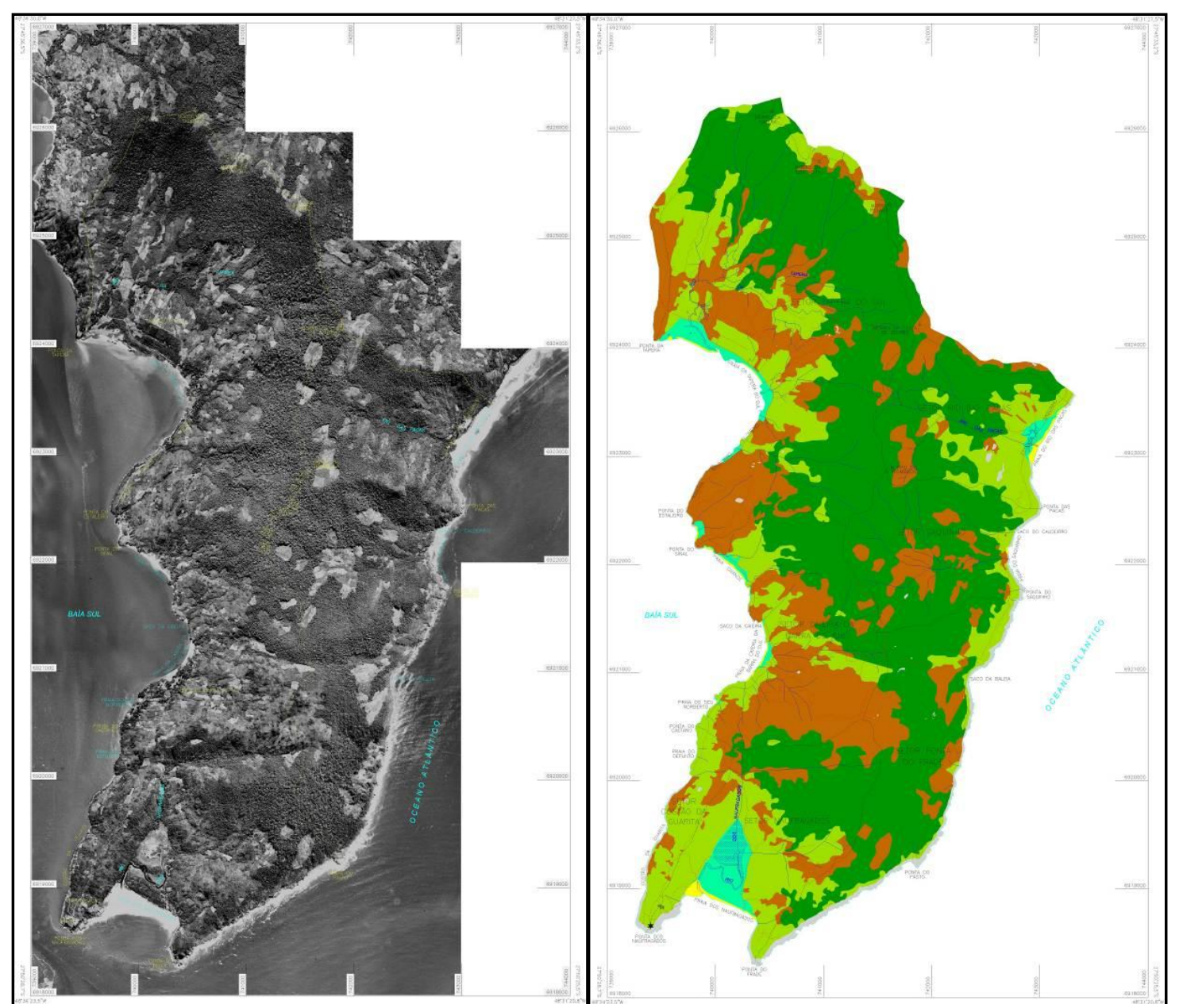

Figura 3 - Mosaico aerofotogramétrico do ano de 1957 (esquerda), com mapa de ocupação, uso e cobertura da terra (direita), onde se observa que as áreas em marrom representam as terras com usos agrícolas e as áreas em verde claro representam as áreas com vegetação em regeneração, originadas a partir de terras agrícolas abandonadas. Nota-se que grandes porções no interior da área de estudo (englobando todas as localidades adjacentes) encontram-se neste processo de regeneração, sendo que as áreas agrícolas passam a ser abandonadas. Fonte: Felix (2005).

Com o passar dos anos, o envelhecimento daqueles que continuaram desempenhando suas funções agrícolas, somado a uma grande ausência de recursos humanos para reposição e manutenção destas práticas, perde-se totalmente o interesse em algumas áreas fora dos limites originais das localidades, fora dos territórios originais. Novamente, as relações de territorialidade dos grupos alteram-se, desta vez, retraindo em áreas, sendo que a paisagem das áreas abandonadas inicia um processo de retomada do aspecto natural, através da regeneração das florestas. Portanto, a área de estudo já se encontrava em processo de retomada da qualidade ambiental, no mínimo, duas décadas antes de ser institucionalizada como UC, conforme veremos a seguir. 


\section{Área de estudo como UC: o desenvolvimento de uma nova territorialidade}

O extremo sul da Ilha de Santa Catarina constitui-se parte integrante do Mosaico de Unidades de Conservação da Serra do Tabuleiro e Terras de Massiambu.Esta UC foi originalmente instituída como deproteção integral, criada pelo Decreto Estadual $\mathrm{n}^{\circ} 1.260$, de 01 de Novembro de 1975, publicado no Diário Oficial do Estado de Santa Catarina DOSC de 07/11/75. No ano de 1977, o Decreto Estadual n² 2.335, de 17 de março de 1977, publicado no DOSC de 23/03/77, anexou um total de $17,10 \mathrm{~km}^{2}$ em terras na área original desta UC, entre estas, o extremosul da Ilha de Santa Catarina.

No ano de 2009, visando o enquadramento desta UC aos preceitos do SNUC, a Lei $n^{\circ} 14.661$ reavaliou e definiu os atuais limites, instituindo o Mosaico de Unidades de Conservação da Serra do Tabuleiro e Terras de Massiambu. Nestes termos, a referida Lei estabeleceu as seguintes unidades de conservação da natureza:

- $\quad$ Parque Estadual da Serra do Tabuleiro - PEST;

- Área de Proteção Ambiental da Vargem do Braço;

- $\quad$ Área de Proteção Ambiental da Vargem do Cedro;

- Área de Proteção Ambiental do Entorno Costeiro do Parque Estadual da Serra do Tabuleiro.

O extremo sul da Ilha de Santa Catarina foi incluído na Área de Proteção Ambiental (APA) do Entorno Costeiro do Parque Estadual da Serra do Tabuleiro, regulamentada pelo Decreto n³.159, de 24 de março de 2010. Portanto, durante 32 anos (de 1977 a 2009), a área de estudo figurou como um território institucionalizado como de proteção integral, passando ao caráter de uso sustentável a partir de 2009.

Conforme expresso anteriormente, o enfraquecimento da economia local, baseada nas atividades agrícolas,ocorrido a partir da década de 1950 e a consequente diminuição de áreas ocupadas, atuaram como fatores determinantes no processo de renaturalização da paisagem. 
Com a inclusão destas áreas, onde a vegetação já se encontrava em processo de regeneração natural, em uma UC de proteção integral (assim foi até a promulgação da Lei $\left.n^{\circ} 14.661 / 2009\right)$, este processo de regeneração é fomentado, na medida em que um novo agente passa a deter o controle sobre este novo território institucionalizado, impondo um novo conjunto de regras. A Figura 4 apresenta importante registro para este estudo de caso, pois fotografias aéreas métricas foram tomadas no mesmo ano da institucionalização da área como UC. Observa-se, portanto, que a área de estudo já se encontrava em plena retomada da qualidade ambiental quando foi incluída nos limites de uma UC, sendo esta retomada representada pela re-naturalização da paisagem.

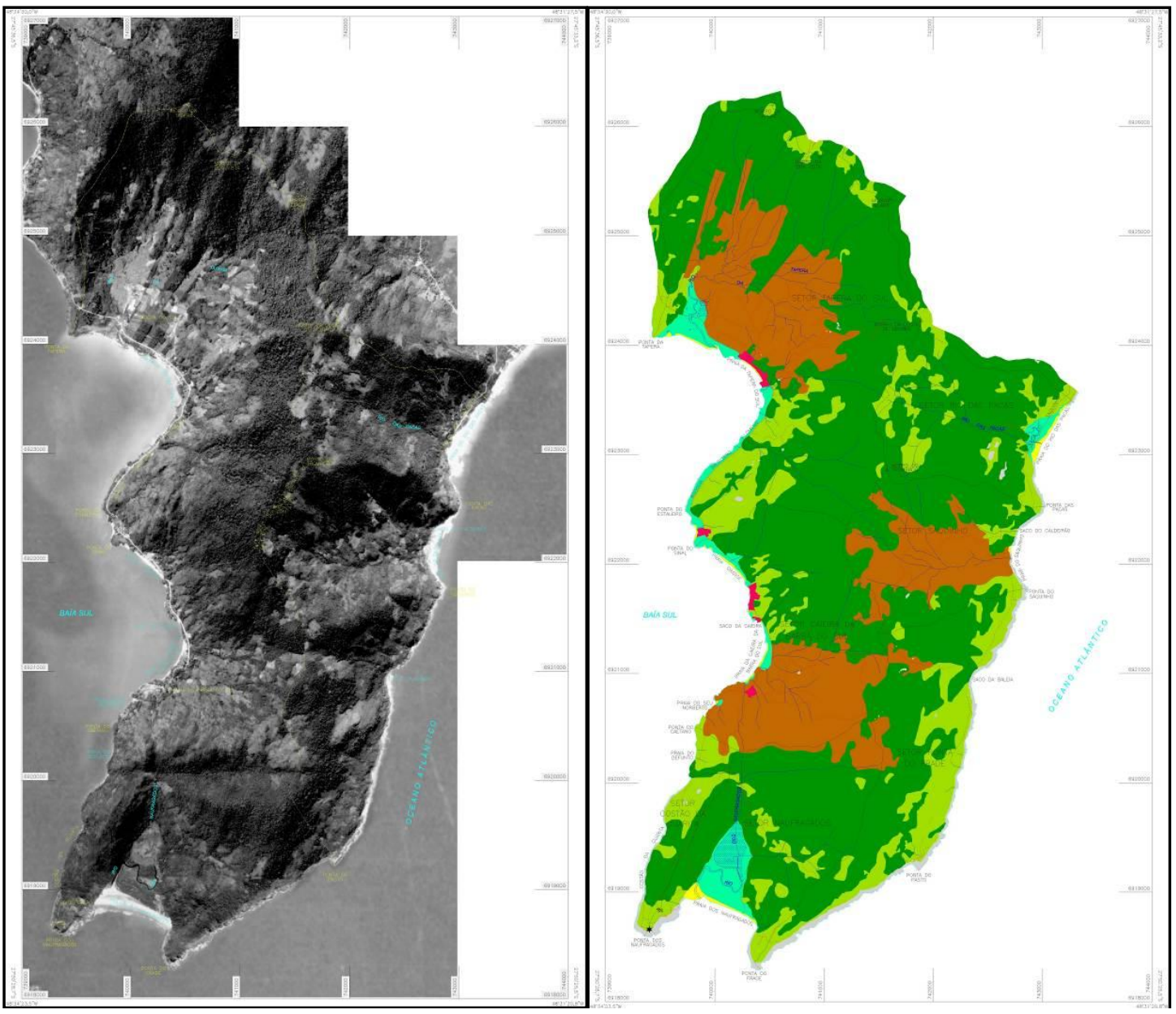

Figura 4 - Mosaico aerofotogramétrico do ano de 1977 (esquerda), com mapa de ocupação, uso e cobertura da terra (direita), onde se observa que as áreas em marrom representam as terras com usos agrícolas; as áreas em verde claro representam as áreas com vegetação em regeneração, originadas a partir de terras agrícolas abandonadas; as áreas em verde escuro representam as áreas de florestas em estágios médio e avançado de regeneração natural. Nota-se o surgimento dos núcleos urbanizados (áreas em magenta nas as localidades adjacentes) e que as grandes porções no interior da área de estudo, que se encontravam como terras agrícolas abandonadas, já apresentam caráter de recuperação e regeneração ambiental. Fonte: Felix (2005). 
Impõe-se,então, uma nova territorialidade: os fatores que caracterizavam aqueles territórios, formados por terras que outrora foram cultivadas e que pertenciam a alguns “donos”, não mais existem; o território passa a ser tachado como tal por ser uma área destinada à conservação da natureza.

Não se pretende questionar o importante papel desempenhado pela institucionalização daquela área em relação à continuidade da regeneração da natureza, da re-naturalização da paisagem. Porém, deve-se ressaltar o fato de que o controle em relação à deliberação e tomada de decisões no momento de criação da UC não foi delegado de forma direta pelos grupos sociais locais e, sim, de forma indireta, quando do sufrágio universal que apontou os representantes políticos destes grupos.

Sendo assim, nem sempre e nem todos respeitam o conjunto de regras, tampouco, respeitam aquele que está investido do controle sobre o território de uma UC, no caso, o Estado. Daí é que surgem os conflitos, materializados principalmente através de invasões e ocupações irregulares de áreas, quadro intensificado pela omissão do mesmo Estado em relação à fiscalização e manutenção de seu controle territorial, de sua territorialidade, onde suas ações se restringem a medidas corretivas como demolições de construções irregulares.

No extremo sul da Ilha de Santa Catarina, em áreas atualmente ocupadas pela APA do Entorno Costeiro do Parque Estadual da Serra do Tabuleiro, apesar de não se observar quaisquer atividades antrópicas de grande porte, o local vem sendo alvo de exploração por oferecer condições perfeitas para a prática de esportes como o surfe e o trekking, além de ser lugar ideal para acampamentos. Estas atividades, juntamente com a pesca e a procura de um lugar seguro e tranquilo para passeios e períodos de descanso, têm provocado a proliferação de inúmeras edificações de pequeno porte e precário padrão construtivo no final da trilha principal de acesso e nas proximidades da praia, sobre os cordões litorâneos, alterando e provocando desequilíbrios pontuais nestas áreas (Figura 5).

Este recente processo de ocupação está ocorrendo de forma desordenada no interior da área de estudo, pondo em risco seu equilíbrio ecológico e morfodinâmico, 
sobretudo, na restinga da Praia de Naufragados, tornando-se um problema ambiental que indica o jogo de forças atual em que se encontra o lugar.

Este jogo de forças é representado pela ocupação local, que é considerada irregular e desordenada: irregular, pois os moradores ocuparam áreas sem nenhum título de propriedade, não enfrentando qualquer impedimento por parte do Estado, que deveria fiscalizar o local; e desordenada, pois estes atuais moradores indispõem de uma mínima infraestrutura básica, como água tratada, sistema de tratamento de esgotos e efluentes, abastecimento regular de energia elétrica e transporte público adequado. Este panorama sugere que o controle, presumivelmente, desempenhado pelo Estado em relação à gestão do território correspondente à APA do Entorno Costeiro do Parque Estadual da Serra do Tabuleiro na Ilha de Santa Catarina, não se apresenta plenamente legitimado, desencadeando todos os conflitos posteriores.

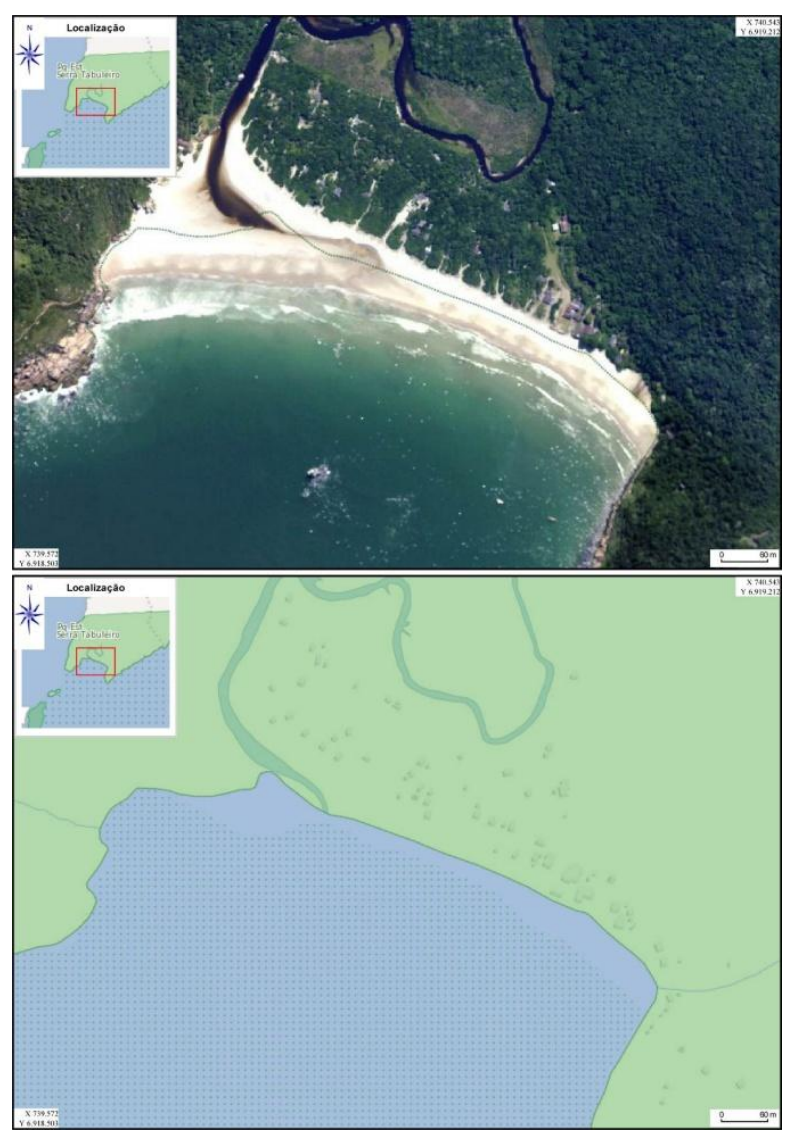

Figura 5 - Detalhe da área de estudo (restinga da Praia dos Naufragados) de acordo com ortofotocarta do ano de 2012, ondese observaa proliferação de edificações de pequeno porte (abaixo em relevo), sendo a maioria de precário padrão construtivo constituindo-se em barracos de madeira com função residencial, caracterizando-se como um processo de ocupação desordenada. Fonte: Adaptadode PMF (2014). 
Por conseguinte, o processo atual de produção da paisagem no interior desta UC encontra-se vinculado a este grande jogo de forçasocorrente. Se, por um lado, a renaturalização da paisagem é um fator inquestionável e marcante nos setores de encosta, por outro, os processos desencadeados pelos conflitos explicados anteriormente, atuam no sentido da artificialização, da inserção de pequenas formas antrópicas em uma paisagem re-naturalizada na planície, originando núcleos de ocupação desordenada que não reconhecem a territorialidade existente. A Figura 6 apresenta o estado de recuperação da área de estudo, já atingido no ano de 2002, mantendo-se neste estado geral até o presente momento.

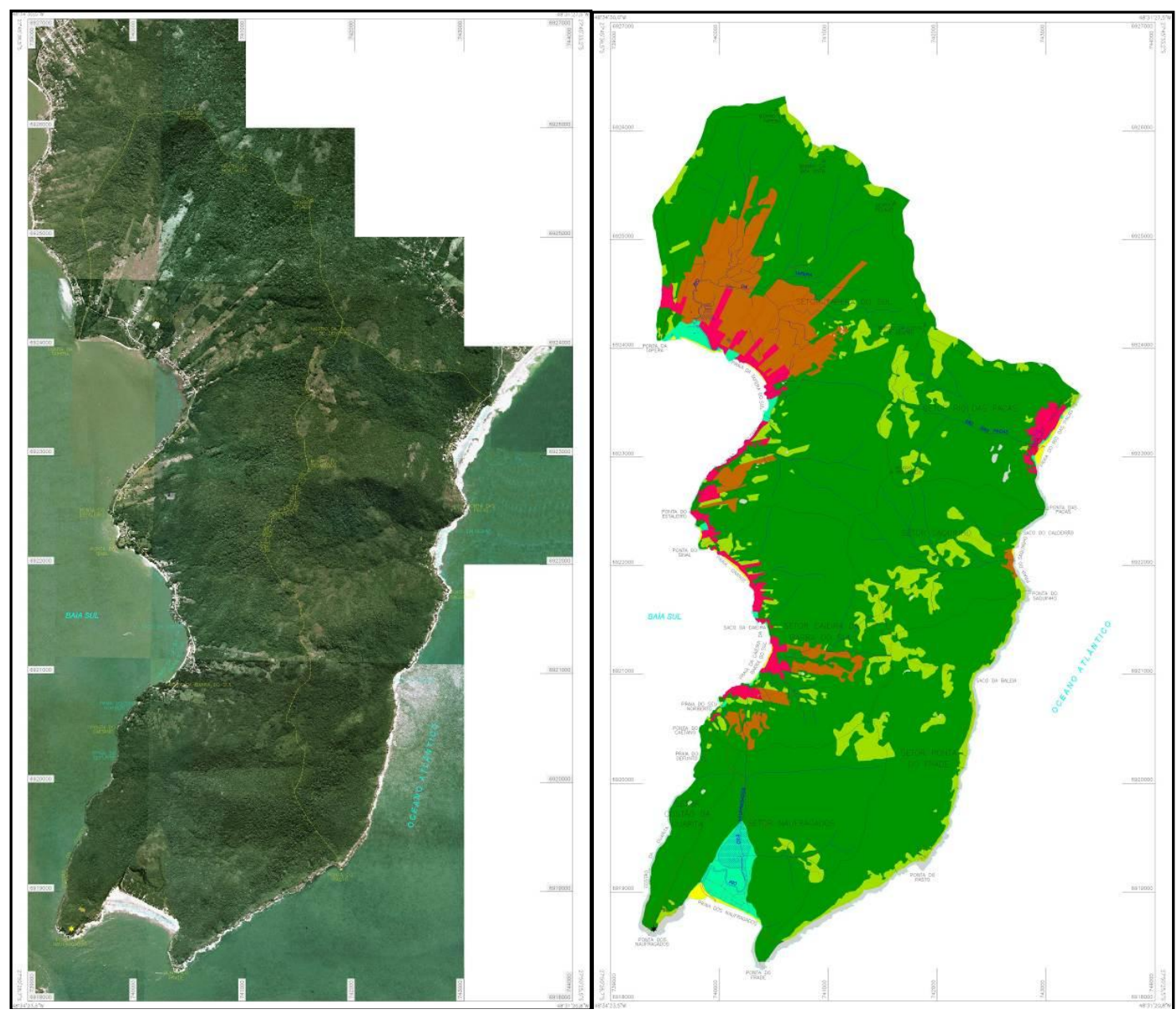

Figura 6 - Ortofotocarta do ano de 2002 (esquerda), com mapa de ocupação, uso e cobertura da terra (direita), onde se observa que as áreas em marrom representam as terras com usos agrícolas; as áreas em verde claro representam as áreas com vegetação em regeneração, originadas a partir de terras agrícolas abandonadas; as áreas em verde escuro representam as áreas de florestas em estágios médio e avançado de regeneração natural. Nota-se a expansão dos núcleos urbanizados (áreas em magenta nas localidades adjacentes) e que a grande maioria das áreas no interior da bacia hidrográfica dos Naufragados apresentam-se quase que plenamente recuperadas. Fonte: Felix (2005). 
Denota-se, portanto, que a ação do Estado enquanto agente dominante, embora tenha gerado diversos conflitos devido às contraposições adotadas frente às territorialidades instituídas, não se concretizou em termos de estabelecimento de uma nova territorialidade de per si. De acordo com o entendimento de Sack (1980), de que a territorialidade depende do por que e de quem está controlando o espaço, a institucionalização da área de estudo como UC, em termos práticos, surtiu efeitos positivos, apenas, como agente auxiliar no processo de re-naturalização da paisagem nos setores de encosta, ao passo que as territorialidades pré-existentes mantiveram suas relações de domínio sobre a área, expressas pela intensificação da ocupação na planície costeira dos Naufragados.

\section{Considerações finais}

O estudo de caso permitiu paralelos interessantes que confirmamalguns ensaios lançados neste trabalho. Porém, deve-se enfatizar que serianecessária a elaboração de investigações desta natureza em variadas UCs, como forma de efetuarem-se estudos comparativos.

Inicialmente, faz-se indispensável uma menção quanto ao teor claro e objetivo da conceituação de território expressa por Souza (1995), de sua construção e desconstrução dentro de escalas temporais diversas, seu caráter cíclico e seus limites instáveis. Todas estas características puderam ser confirmadas e foram expressas quando da elaboração das análises neste trabalho.

Observou-se que o fato de se institucionalizar um determinado espaço, transformando-o em uma UC, por si só, não garante a manutenção de paisagens naturais ou, por analogia, de qualquer tipo de paisagem que se pretenda produzir. A quebra das relações de territorialidade provocadas pela criação de uma UC, ou seja, da materialização prática das relações de uma sociedade com o meio natural, das relações quotidianas dos grupos locais, serve como um fator a mais de produção da paisagem, porém, só se torna determinante com o reconhecimento, por parte dos grupos sociais locais, da nova territorialidade criada. 
No caso da APA do Entorno Costeiro do Parque Estadual da Serra do Tabuleirona Ilha de Santa Catarina, are-naturalização da paisagem não foi desencadeada pela instituição da UC, já que a mesma foi implantada após o abandono de terras agrícolas e início da regeneração natural da vegetação. No entanto, considera-se que a institucionalização daquela área contribuiu para a manutenção da re-naturalização da paisagem.

Porém, como a territorialidade é mantida através de relações de poder sobre as áreas, a manutenção de uma UC prescinde de presença constante do agente ou grupo de controle territorial, no caso o Estado, sob pena do seu território não ser reconhecido, desencadeando conflitos de ocupação e uso de terras conforme os observados no presente estudo de caso.

Na área de estudo, além do fato do Estado ser ausente e deixar de exercer o poder sobre o território da UC, o grupo social que ali se instalou entende que esta ocupação não coloca em risco o equilíbrio ecológico local, tendo em vista os usos relacionados ao turismo de balneário, ao ecoturismo e à pesca que já se constituem em atividades tradicionalmente praticadas na área. Este entendimento corrobora com 0 enfraquecimento da já combalida territorialidade do Estado, depondo contra sua legitimação.

Portanto, conclui-se que apesar de uma UC possuir um território delimitado, os principais fatores atuantes na produção de suas paisagens são as territorialidades, definidas pelo reconhecimento e pelas impressõescaracterísticas de cada grupo social sobre os agentes de controle territorial.

\section{Referências}

BOND, Rosana. A saga de Aleixo Garcia: o descobridor do Império Inca. Florianópolis: Ed. Insular, 1998. 
CLAVAL, Paul. A geografia cultural.Tradução de Luiz Fugazzola Pimenta e Margareth de Castro Afeche Pimenta. 2.ed. Florianópolis: Ed. UFSC, 2001.

COSTA, Rogerio Haesbaert. O mito da desterritorialização: do "fim dos territórios" à multiterritorialização. Rio de Janeiro: Bertrand Brasil, 2004.

FELIX, Alexande; LISBOA, Cristiane Kleba; MARQUES,Cledson A.; RODRIGUES, Lilian. Compartimentação geomorfológica de Cacupé e localidades adjacentes Florianópolis/SC. In: CONGRESSO BRASILEIRO DE GEÓGRAFOS, VI.Eixo 2. Goiânia GO, 18 a 23 de julho de 2004, Anais...Goiânia: Gráfica da Universidade Federal de Goiás 2004.

FELIX, Alexandre. Parque Estadual da Serra do Tabuleiro: proposta de revisão dos limites na Ilha de Santa Catarina. Trabalho de Conclusão de Curso (Graduação em Geografia) Universidade Federal de Santa Catarina, Departamento de Geociências, Florianópolis, 2005.

FELIX, Alexandre. Determinação dos limites de ocorrência dos setores morfodinâmicos ao longo do arco praial dos Naufragados, Ilha de Santa Catarina/SC Brasil. Dissertação (Mestrado em Geografia) -Universidade Federal de Santa Catarina. Departamento de Geociências, Florianópolis, 2010.

HERRMANN, Maria Lúcia de Paula; ROSA, Rogerio de Oliveira. Mapeamento temático do município de Florianópolis - Geomorfologia. Florianópolis: IPUF. 1991.

IPUF. Instituto de Planejamento Urbano de Florianópolis. Guia digital Floripa. Florianópolis, 2001.

PEREIRA, Nereu do Vale; PEREIRA, Francisco do Vale; SILVA NETO, Waldemar Joaquim da. Ribeirão da Ilha - vida e retratos: um distrito em destaque. Florianópolis: Fundação Franklin Cascaes, 1991.

PIAZZA, Walter Fernando. A epopéia açórico-madeirense (1747-1756). Florianópolis: Ed. UFSC/Lunardelli, 1992.

PMF. PREFEITURA MUNICIPAL DE FLORIANÓPOLIS. Geoprocessamento. Disponível em: <http://geo.pmf.sc.gov.br/>. Acesso em: 21 dez. 2014.

RÖPER, Monika. Geografia social e unidades de conservação: reflexões teóricas e exemplos da bacia do Alto Rio Paraguai (Mato Grosso). Geosul, Florianópolis, v. 14, n. 27, p.45-66, 1999.

SACK, Robert David. Human territoriality: its theory and history. Cambridge: Cambridge University Press, 1980. 
SANTA CATARINA. Decreto Estadual $n^{\circ}$ 1.260, de 01 de novembro de 1975. Diário Oficial de Santa Catarina de 07/11/75. Florianópolis, 1975.

SANTA CATARINA. Decreto Estadual n².335, de 17 de março de 1977.Diário Oficial do Estado de Santa Catarina de 23/03/77. Florianópolis, 1977.

SANTOS, Milton. Metamorfoses do espaço habitado: fundamentos teóricos e metodológicos da geografia. 4.ed. São Paulo: Ed. Hucitec, 1996.

SAUER, Carl Ortwin. The Morphology of landscape. Publications in Geography, Califórnia: University of Califórnia, v. 2, n.2. p. 296-315, 1925.

SOUZA, Marcelo L. de. O território: sobre espaço e poder, autonomia e desenvolvimento. In: CASTRO, Iná; GOMES, Paulo; CORRÊA, Roberto (Org.).Geografia: conceitos e temas.Rio de Janeiro: Bertrand Brasil, 1995.

VÁRZEA, Virgílio. Santa Catarina - a Ilha. Companhia Typographica do Brasil. Rio de Janeiro, 1900. 